\title{
Druckfehler -Verzeichnis.
}

In der Abhandlung Niosi, Die Mesenterialzysten ete., S. 217-338 dieses Bandes, sind folgende Druckfehler zu verbessern.

Es soll stehen:

Seite 226 Zeile 3 v. o. statt $7 \mathrm{~cm}$

" 230 " 19 v. u. " Fig. 8, Taf. X

" 230 " 13 v. u. " dieser Zellen

" $230 " 5$ v. 'u. " Fig. 8, Taf. X

"231 " 18 v. o. " Fig. 9, Taf. $X$

" 231 " 17 v. u. " Fig. 9, Taf. X

" 243 " 8 v. $0 . \quad$ " Sie haben Zilien und starke Sekretion

" $247 \quad 4$ v. $0 . \quad$ mit Pflasterepithel

" $264 \quad 9$ v. o. " (Hydrosalpinx)

" $265 " 14$ v. $0 . "$ perinäaler

, $285 " 4$ v. o. " waren die richtig $7 \mathrm{~mm}$

"Fig. 8, Taf. VII

" dieser Zellhaufen

" Fig. 8, Taf. VII

" Fig. 9, Taf. VIII

" Fig. 9, Taf. VIII

" Sie haben starke

Sekretion und keine Zilien. mit kubischem Epithel (Hydroparasalpinx)

" perirenaler

" waren nicht die 